\title{
ESTUDO ESPACIAL DO GRADIENTE DE VEGETAÇÃO DO PARQUE ESTADUAL DA ILHA DO CARDOSO, SP, BRASIL
}

\section{SPATIAL STUDY OF THE VEGETATION GRADIENT FROM CARDOSO ISLAND STATE PARK, SP, BRAZIL}

\section{Bernardi, J. V. E. ${ }^{1}$, Landim, P.M.B. ${ }^{2}$, Barreto, C.L. ${ }^{3}$; Monteiro, R.C. ${ }^{4}$}

${ }^{1}$ Universidade Federal de Rondônia/Porto Velho, RO, e-mail: labmerc@unir.br ${ }^{2,4}$ Universidade Estadual Paulista/Rio Claro, SP.

${ }^{3}$ Instituto Brasileiro do Meio Ambiente e dos Recursos Naturais Renováveis/IBAMAFLONA, Humaitá, AM.

\section{RESUMO}

O enfoque deste trabalho é a utilização de técnicas de sensoriamento remoto na obtenção de um mapa temático da vegetação, em escala do Parque Estadual da Ilha do Cardoso, situado no litoral sul paulista, com vistas a um estudo espacial dos tipos de vegetação presentes e sua distribuição em área. A partir da análise conjunta do mapa temático com os tipos de vegetação, das composições coloridas e do índice de vegetação por diferença normalizada (IVDN), pode-se concluir que os tipos de vegetação existentes encontram-se em um franco estado de sucessão ecológica com vários mosaicos desde a planície costeira até a região serrana. O gradiente de vegetação encontrado está relacionado com os diferentes tipos de substratos, com limites dos tipos de vegetação coincidentes, indicando uma dependência pedológica espacial. Os tipos de vegetação na planície costeira correspondem à pioneira de dunas e restinga de $s c r u b$ em Neossolos Quatzarênicos Hidromórficos típicos e vegetação arbórea de restinga em Espodossolos Ferrocárbicos Hidromórficos hísticos. No sopé da região montanhosa, encontra-se floresta pluvial tropical de planície litorânea em Neossolos Flúvicos Distróficos típicos. Para a área montanhosa ocorre floresta pluvial tropical de encosta em Argilossolos Amarelos Distróficos câmbicos, Argilossolos Vermelho-Amarelos Distróficos abrúpticos, Cambissolos Hísticos Distróficos típicos e vegetação arbustiva em Neossolos Litólicos Hísticos típicos. Apesar da vegetação de mangue ter sido evidenciada nas imagens digitais, não foi possível um acompanhamento detalhado de campo.

Palavras chaves: Gradiente de vegetação, sensoriamento remoto, modelagem tridimensional, Ilha do Cardoso. 


\begin{abstract}
The focus of this work is the application of remote sensing techniques to thematic map making of the Cardoso Island State Park, located in the southern coast of São Paulo State, regarding a spatial study of vegetation types. It can be concluded, from the thematic map, color compositions and NDVI (normalized difference of vegetation index), that the existent vegetation types are in a ecological sequence with several mosaics from the coastal plain to the mountainous area. The vegetation gradient found is related with the different substratum types indicating pedological space dependence. In the coastal plain the corresponding vegetation are pioneering in dunes and scrub sandbank over typical Neossolos Quatzarênicos Hidromórficos and sandbank arboreal vegetation over Espodossolos Ferrocárbicos Hidromórficos. In the foothill area the vegetation is tropical pluvial forest of coastal plain over typical Neossolos Flúvicos Distróficos. For the mountain area occurs tropical pluvial forest of hillside over Argilossolos Amarelos Distróficos Câmbicos, Argilossolos VermelhoAmarelos Distróficos Abrúpticos and typical Cambissolos Histicos Distróficos and shrubby vegetation in typical Neossolos Litólicos Histico". In spite of the swamp vegetation evidenced in the digital images, it was not possible a detailed checking in field works.
\end{abstract}

Key-words: Vegetation gradient, remote sensing, 3D modelling, Cardoso Island.

\title{
1. INTRODUÇÃO
}

O enfoque principal deste trabalho é a utilização de técnicas de sensoriamento remoto na obtenção de um mapa temático da vegetação do Parque Estadual da Ilha do Cardoso, situado no litoral sul paulista, com vistas a um estudo espacial dos tipos de vegetação presentes na área. Bernardi (2001) estudou quantitativamente a estrutura da vegetação do Parque e apresentam em seu trabalho detalhes sobre a área.

O estudo espacial em três dimensões permite a visualização e a interpretação mais acurada de características do terreno e a construção de Modelos Digitais de Elevação (MDE), a partir de dados altimétricos. Estas superfícies tridimensionais geradas reproduzem características do relevo possibilitando maior clareza à respectiva percepção geomorfológica. Desse modo a integração dos MDE a outras informações, tais como mapas temáticos elaborados a partir de imagens de sensoriamento remoto, oferece melhores possibilidades de a avaliação de influências recíprocas.

A vegetação é o primeiro alvo a interagir com a radiação eletromagnética, exibindo um comportamento espectral característico facilitando, desse modo, a sua identificação. As reflectâncias das coberturas vegetais, segundo Goyot (1995), depende das propriedades ópticas das plantas e do arranjo destas no espaço. Estudos 
feitos por Campbell (1987) mostraram que os vários tipos de comunidades vegetais respondem de forma diferente quanto às suas reflectâncias.

Assim, a aplicação de técnicas de sensoriamento remoto permite identificar nitidamente a diferença de textura e de estrutura da vegetação como árvores, arbustos e herbáceos. Para interpretar dados de sensoriamento remoto de dosséis de florestas é necessário, portanto, o conhecimento dos fatores que afetam suas propriedades óticas, que podem ser externos ou internos ao dossel (GOEL, 1988; GOYOT et al.1989). Estes autores citam os seguintes fatores externos como sendo os mais importantes: ângulos azimutais e zenitais de iluminação da cena; tamanho da área imageada e ângulo de visada do sensor; condições atmosféricas. Entre os fatores internos mencionam a arquitetura do dossel e as propriedades espectrais da superfície do terreno.

A classificação de imagens multiespectrais de sensoriamento remoto associa cada pixel da imagem a um rótulo, descrevendo um objeto real (vegetação, solo, etc.). Dessa forma, os valores numéricos (VNs) associados a cada pixel, definidos pela reflectância dos materiais que compõem esse pixel, são identificados em termos de um tipo de cobertura da superfície terrestre obtido pela imagem (água, tipos de vegetação, de solo, de rocha, etc.), chamadas então de tema (CRÓSTA, 1993). Quando esse tipo de operação é efetuado para todos os pixels de uma determinada área, o resultado é um mapa temático, mostrando a distribuição geográfica de um tema, como vegetação ou solo. Neste caso, denota-se que, uma imagem de sensoriamento remoto classificada é uma forma de mapa temático digital. Deve ser enfatizado, porém, que a utilização da classificação supervisionada implica que o usuário conheça parte da área a ser classificada, antes de iniciar o processo de classificação. Este conhecimento específico chama-se verdade terrestre e quando uma área é identificada pelo usuário, representando uma classe, denomina-se área de treinamento. Os valores numéricos (VNs) dos pixels do conjunto de treinamento em cada uma das bandas espectrais são então comparados com os VNs de cada pixel da imagem, decidindo à qual classe estes pertencem.

Índices de vegetação (IV) são medidas quantitativas, relacionadas aos valores digitais, que indicam a biomassa ou o vigor vegetativo das plantas (CAMPBELL, 1987). São obtidos a partir de medidas radiométricas de vegetação, utilizadas para avaliar variações temporais e espaciais de dados biofísicos. A base física para obtenção dos índices de vegetação está relacionada à absorção pela clorofila da planta, da porção de radiação eletromagnética na região espectral do vermelho e ao espalhamento pelas folhas das plantas da radiação na região espectral do infravermelho próximo. Desta forma, cada banda é um indicador do total de vegetação presente em uma área, porém contribuições do solo e da atmosfera fazem com que ocorra uma incerteza na estimativa dos parâmetros biofísicos da vegetação (LIU e HUETE, 1995). Os índices de vegetação podem ser calculados a partir de dados de saída de voltagem, valores de radiância, valores de reflectância e números digitais de imagens de satélites, sendo todos corretos, mas cada um produzirá um valor diferente do índice de vegetação para as mesmas condições de superfície (XAVIER, 1998). 
O índice de vegetação proposto por Tucker (1979), denominado de índice de vegetação de diferença normalizada (NDVI ou IVDN), mede o vigor e abundância da vegetação. Este índice é avaliado pelas medidas de reflectância na faixa espectral do verde e do vermelho $(\mathrm{G} / \mathrm{R})$ ou infravermelho próximo e vermelho (IR/R) que é mais funcional (CAMPBELL, 1987). OS Ivs têm grande aplicabilidade na separação de diferentes tipos de vegetação por sensoriamento remoto e muitos autores têm se utilizado desta técnica, o que a torna mais confiável. Porém, para que estes índices sejam interpretados com precisão são necessários o conhecimento de campo e a experiência no tratamento e interpretação das imagens.

No presente trabalho são enfatizadas as técnicas aplicadas para a obtenção de um mapa de vegetação do Parque Estadual da Ilha do Cardoso e os resultados obtidos em termos de identificação dos diferentes tipos de vegetação existentes na Ilha. São discutidas também, as relações espaciais entre os tipos de vegetação identificados e os demais componentes fisiográficos (solos, relevo e rochas).

\section{DESCRIÇÃO DA ÁREA DE ESTUDO}

O Parque Estadual da Ilha do Cardoso (PEIC), administrado pelo Instituto Florestal da Secretária do Meio Ambiente do Estado de São Paulo, localiza-se no litoral sul do Estado de São Paulo na divisa com o Estado do Paraná, abrangendo uma área aproximada de $151 \mathrm{~km}^{2}$, situando-se entre as coordenadas $48^{\circ} 05^{\prime} 42^{\prime \prime} \mathrm{W}$, $25^{\circ} 03^{\prime} 05^{\prime \prime} \mathrm{S}$ e $48^{\circ} 53^{\prime} 48^{\prime \prime} \mathrm{W}, 25^{\circ} 18^{\prime} 18^{\prime \prime} \mathrm{S}$, separado do continente pelo canal de Trapandé. A localização e vias de acesso ao Parque têm como referência os municípios de Cananéia e de Ilha Comprida (Figura 1).

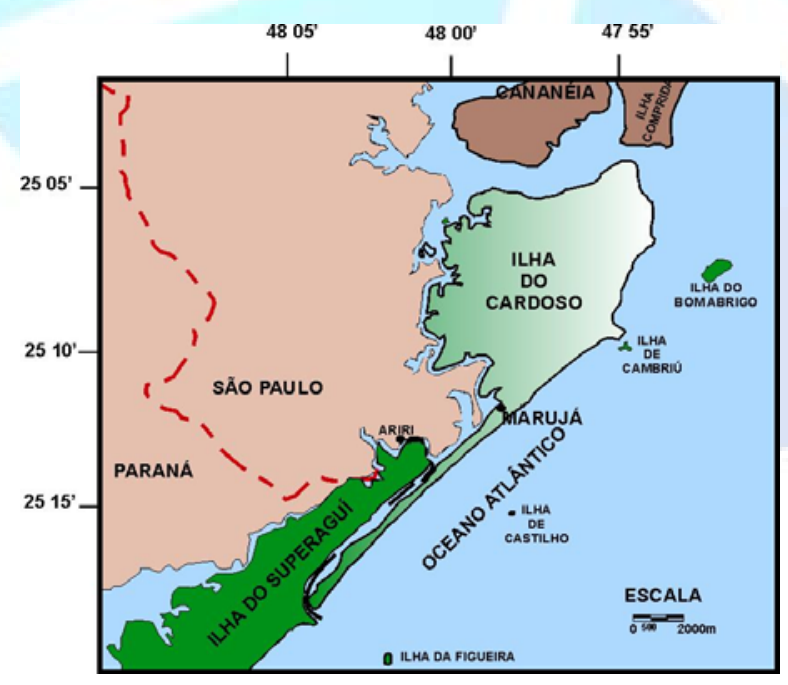

Figura 1 - Localização do Parque Estadual da Ilha do Cardoso (modificado de WEBER, 1998).

A topografia da Ilha é predominantemente montanhosa, com a parte central dominada por elevações acima de $814 \mathrm{~m}$. O clima é megatérmico superúmido, sem 
estação seca definida e com nível de precipitação anual de $3.000 \mathrm{~mm}$ (FUNARI et al., 1987).

\subsection{Caracterização geológica}

A geologia da ilha do Cardoso é constituída principalmente por um complexo ígneo alcalino caracterizado, por weber (1998), como Sienito Três Irmãos (STI) aflorante na porção central da ilha, ocupando sua maior parte, e Granito Cambriú (GC) na porção leste da Ilha. As litologias encontradas são quartzo-monzonito, quartzo-sienito, monzonito, sienito sienogranito e monzogranito, os quais em geral, apresentam estruturas fluidal e xenomórfica.

$\mathrm{Na}$ porção setentrional encontra-se uma faixa de rochas metas sedimentares fácies xisto verde correlacionadas por weber (1998) às rochas da Formação Rio das Cobras. Essas rochas metassedimentares do sub-domínio Iguape, anteriormente correlacionados à seqüência Turvo-Cajatí, são chamadas Metassedimentos Iguape. Ocorrem também na Ilha, rochas cenozóicas da Formação Cananéia, representadas por arenito grosso, mal selecionado com estratificações cruzadas intensamente bioperturbadas, com bandas ricas em minerais pesados. Em geral as porções marginais norte, leste e sul da ilha, são cobertas por sedimentos quaternários de baixos terraços marinhos, flúvio-lagunares e mangues.

\subsection{Caracterização Geomorfológica}

A Ilha do Cardoso apresenta basicamente cinco compartimentos geomorfológicos distintos, distribuídos em três domínios geomorfológicos, relacionados diretamente com os tipos litológicos (WEBER,1998; KARMANN et al., 1999).

No primeiro domínio o compartimento é montanhoso, desenvolvido em rochas sienito-monzoníticas, formando topos angulosos com vertentes retilíneo-convexas, ocupando uma área de $68 \mathrm{~km}^{2}$, estendendo-se da região oriental até o oceano a leste, formando costões rochosos, onde ocorrem terraços de abrasão marinha além de grandes matacões, conforme descrito por Petri e Fulfaro (1970). As cristas elevadas podem atingir cotas altimétricas superiores a $814 \mathrm{~m}$. A rede de drenagem é muito densa e encaixada no conjunto de fraturas de direção preferencial NE-SW, NW-SE e W-E, em calhas retilíneas e com alto gradiente de inclinação em torno de $86^{\circ}$ a praticamente $90^{\circ}$ formando diversas cachoeiras, com quedas superiores a $40 \mathrm{~m}$.

$\mathrm{O}$ segundo domínio é representado principalmente pelo compartimento de morros baixos arredondados, com inclinação média aproximada de $45^{\circ}$ a $60^{\circ}$, associado às rochas metamórficas da ilha. As vertentes destes morros são côncavas e sua rede de drenagem obedece ao fraturamento com as mesmas direções do primeiro compartimento. Este compartimento ocupa uma parte da porção setentrional da Ilha, com afloramentos de rochas metamórficas de baixo grau representadas por metarritmitos, xistos e filitos, intercalados por lentes de quartzitos. 
O terceiro domínio é representado pela planície costeira, que pode ser subdividido em três compartimentos: áreas de mangue; praias; e cordões arenosos. As áreas de mangue ficam localizadas a oeste da Ilha, entre os canais fluviais e a planície de maré. As praias geralmente são recortadas por costões rochosos do domínio montanhoso, e localizam-se a leste e sudeste da área. Os cordões litorâneos quartzoarenosos formam localmente pequenas dunas por ação do retrabalhamento eólico, no sul da ilha, destacando-se a formação de uma restinga arenosa com extensão aproximada de $18 \mathrm{~km}$ por $500 \mathrm{~m}$ de largura, com altitudes em torno de 3 a $10 \mathrm{~m}$. A drenagem da planície costeira é de baixo gradiente, com canais meandrantes e localmente entrelaçados por influência da maré.

\subsection{Caracterização Pedológica}

Adotando a classificação proposta pela "Empresa Brasileira de Pesquisa Agropecuária - EMBRAPA" (1999), são reconhecidas na Ilha 7 unidades taxonômicas: Cambissolos Hísticos Distróficos típicos, encontrados acima da cota topográfica de 500 metros com profundidades variando entre 50 a 80 centímetros; Argilossolos Amarelos Distróficos câmbicos encontrados na região serrana acima da cota topográfica de 350 metros e com profundidades superiores a 2 metros para o horizonte B; Argissolos Vermelho-Amarelos Distróficos abrúpticos encontrados nos morros associados aos metarritimitos e com profundidade superior a 2,5 metros para o horizonte B; Espodossolos Ferrocárbicos Hidromórficos hísticos encontrados na planície costeira onde se localiza a Floresta Pluvial Tropical da Planície Costeira, cujo horizonte orgânico ultrapassa em média 25 centímetros de profundidade; Neossolos Flúvicos Distróficos típicos, encontrados nos sopés dos morros associados aos metarritimitos; Neossolos Quartzarênicos Hidromórficos típicos, encontrados nas proximidades das regiões de Dunas na planície costeira; e Neossolos Litólicos Hísticos típicos encontrados, nas regiões escarpadas associadas à ocorrência de afloramentos rochosos da região serrana. Ocorrem ainda duas classes, mangue e duna, que podem ser consideradas como depósitos sedimentares não pedogeneizados.

\subsection{Caracterização da Vegetação}

Os dados florísticos disponíveis para a Ilha do Cardoso são bastante escassos, ainda hoje, apesar do número relativamente grande de trabalhos que vêm sendo desenvolvidos em locais específicos, próximos a Base do Parque Estadual. No entanto, é importante salientar, a valiosa contribuição do grupo de pesquisadores do Instituto de Botânica e do Instituto Florestal, pelos estudos efetuados das famílias vegetais fanerogâmicas, que ocorrem nas diversas formações vegetais presentes na Ilha. As listas de espécies publicadas pelos dois Institutos contribuíram para a identificação das fisiografias da vegetação e de sua distribuição, durante a confecção do mapa temático dos tipos de vegetação realizado no presente estudo.

Na Ilha são identificados sete tipos de vegetação descritos, a seguir, a partir da linha de praia até os topos da região montanhosa. 


\subsubsection{Vegetação Pioneira de Dunas}

A vegetação que fixa as elevações de areias nas praias litorâneas brasileiras tem sido geralmente denominada vegetação pioneira de dunas. $\mathrm{Na}$ Ilha do Cardoso esta formação florestal distribui-se principalmente a nordeste, nas praias entre a Barra de Cananéia e a Ponta do Itacuruçá, e a sul-sudeste, entre a Vila de Marujá e a Barra do Ararapira (NOFFS e BAPTISTA-NOFFS, 1982). Barros et al.(1991) as classifica como plantas psamófitas e halófitas, caracterizando-se por serem estoloníferas e rizomatosas. Outra característica presente nestas plantas refere-se ao sistema radicular extenso. Estas espécies pioneiras suportam condições extremas resistentes de insolação e salinidade, sendo bem adaptadas a estas condições. Afastando-se da linha de praia, a vegetação torna-se mais densa e diversificada em conseqüência da diminuição da salinidade e maior consolidação do substrato. Entre as espécies mais significativas destacam-se Spartina ciliata (Graminia), Iponea pes-caprea (Convolvulaceae), Hydrocotyle bonariensis (Umbelliferae), Acicarpha spathulata (Calyceraceae), Diodia teres e Diodia radula (Rubiaceae).

\subsubsection{Vegetação de Restinga}

A vegetação de restinga cobre a maior parte da planície arenosa da Ilha do Cardoso, principalmente a região norte-nordeste (Restinga do Pereirinha) e também a porção sul-sudeste. Apresenta-se como um complexo de diferentes comunidades vegetais que se interpenetram (DE GRANDE e LOPES, 1981).

A Restinga do Pereirinha é caracterizada por uma vegetação predominantemente florestal, que inclui desde formações arbóreas bastante abertas e baixas, com 4-5m de altura, até formações arbóreas fechadas, sombreadas no interior, com mais de $15 \mathrm{~m}$ de altura, onde a camada de húmus e serrapilheira é bastante espessa. Barros et al. (1991), descreveram uma formação mais arbustiva na porção baixa do pós-praia dominada por Dalbergia ecastaphyllum, Sophora tomentosa e Tibouchina holosericea. Trata-se de uma vegetação baixa (1,0 a 1,5 m de altura) com indivíduos espaçados ou não entre si, sobre um substrato arenoso. Este tipo de vegetação de restinga pode ser denominado de "scrub" ou arbustiva.

As áreas de restinga mais aberta são bem iluminadas no interior apresentando árvores com altura média de 5 metros, bem ramificadas a partir da base, o que proporciona um estrato herbáceo bastante conspícuo, onde predominam pteridófitas e algumas bromélias. $\mathrm{O}$ solo é arenoso, com fina camada de húmus $(2 \mathrm{~cm})$, e sua drenagem é geralmente mais lenta, devido à baixa declividade, principalmente no verão onde permanece por longo tempo encharcado. Já na área de restinga com vegetação de floresta mais fechada, observa-se a presença de árvores mais altas, com altura média de 9 metros, chegando por vezes ao intervalo 12-15 metros. O dossel é mais contínuo em relação à restinga aberta, existindo maior quantidade de epífitas (bromeliáceas, orquidáceas e gesneriáceas), e com estrato herbáceo predominantemente constituído de bromeliáceas e orquídeas. 


\begin{tabular}{|l|r|}
\hline Recebido em: 10/12/2003 & HOLOS Environment, v.5 n.1, 2005 - P. 8 \\
\hline Liberado para Publicação em: 12/10/2005 & ISSN: $1519-8634$ \\
\hline
\end{tabular}

$\mathrm{Na}$ Vegetação de Restinga a família Myrtaceae é a que apresenta maior número de espécies onde se destacam: Myrcia bicarinata, Eugenia umbelliflora, entre outras. Entretanto, as famílias Guttiferae, Bromeliaceae e Ericaceae são também representativas. A família Bromeliaceae ocorre tanto nas áreas mais abertas, como nas áreas mais sombreadas onde o dossel apresenta-se contínuo. Já as famílias Guttiferae e Ericaceae apresentam-se principalmente nas áreas mais abertas, sendo que na família Guttiferae a presença de Clusia criuva, sobressai na fisionomia da área como uma das espécies mais importantes na comunidade vegetal.

As características fisionômicas da comunidade que compõe a vegetação de restinga estão relacionadas com as condições ambientais da área, notadamente as edáficas. As condições limitantes do solo refletem-se na vegetação, que apresenta escleromorfismo, nanismo e sistema radicular superficial. O componente arbóreo apresenta pequena complexidade estrutural e diversidade específica baixa, com um número pequeno de espécies representado por muitos indivíduos (Figura 2).

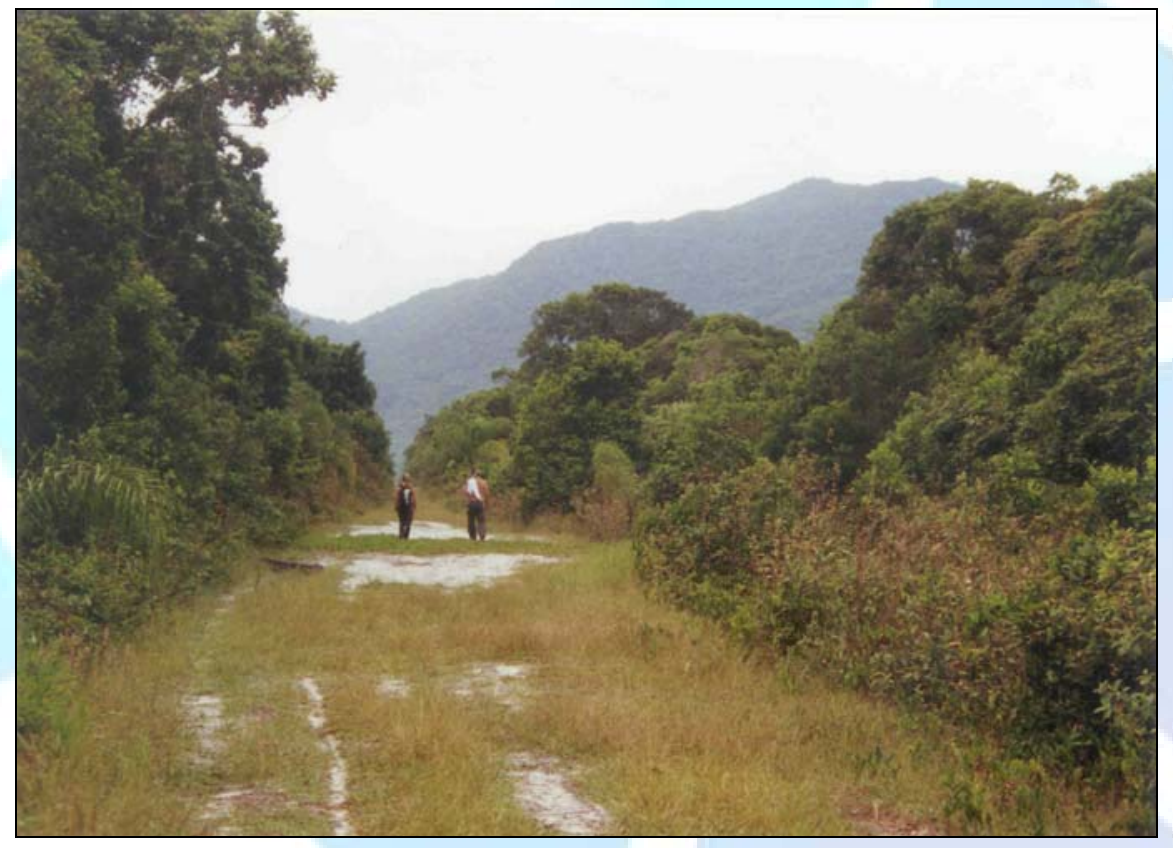

Figura 2 - Vegetação de Restinga Arbórea. (foto - J.V.E.Bernardi)

\subsubsection{Floresta Pluvial Tropical da Planície Litorânea}

A Floresta Pluvial Tropical da Planície Litorânea é um tipo de formação florestal relacionado a uma vegetação "intermediária" em termos fisionômicos, condicionada pelo estágio de desenvolvimento do solo. Ocorre em uma zona de transição restinga-floresta e apresenta a vegetação arbórea composta por espécies típicas, tanto da restinga como da floresta de encosta.

De Grande e Lopes, (1981) assinalam que a transição da restinga para a floresta é gradativa e caracterizada pelo desaparecimento da vegetação de cobertura do solo, ao mesmo tempo em que a camada de serrapilheira torna-se mais espessa e há uma regressão das características xerofíticas. 
A Floresta de Planície é composta de dois estratos arbóreos mais ou menos contínuos, com dossel fechado, grande quantidade de epífitas e lianas e estrato arbustivo-herbáceo denso.

Nas faixas de transição é freqüente a presença de Podocarpus sellowii e Clletha scabra. No estrato arbustivo e arbóreo pode-se encontrar Heliconia velloziana e Calathea longibracteata. O estrato arbóreo superior pode atingir até 20 metros.

\subsubsection{Floresta Pluvial Tropical de Encosta}

A Floresta Pluvial Tropical de encosta, segundo Camargo et al. (1972) é constituído de por três estratos: o superior com 25-30 metros de altura, o médio com 10-12 metros e o inferior (sub-bosque), com menos de 2 metros.

Estudos realizados por Melo e Mantovani (1994) indicam a ocorrência de três estratos arbóreos mais ou menos contínuos: o inferior com 5-10 metros de altura, o médio com 15-21 metros, e o superior com 24-28 metros. Além desses, três estratos, ocorrem árvores emergentes com mais de 30 metros e um estrato arbustivo-herbáceo de porte baixo. O Schizolobium parahyba, Macherium nictitans, Cariniana estrellensis e Virola oleifera são algumas das espécies emergentes. No estrato superior (dossel) ocorrem com freqüência, Cryptocaria moschata, Rapanea umbellata, Casearia obliqua e Sloanea guianensis. No estrato médio aparecem, por exemplo, Gomidesia spectabilis, Cabralea canjerana e Ilex theezans. O estrato inferior é constituído por arvoredos representados principalmente por Rudgea jasminioides e Psychotria nuda. Na Floresta de Encosta a presença de Euterpe edulis é freqüente e chega em alguns pontos a representar cerca de $20 \%$ dos indivíduos identificados em estudos fitossociológicos (MELO e MANTOVANI, 1994).

$\mathrm{Na}$ área de estudo, a Floresta Pluvial Tropical (Figura 3) cobre as encostas e topos mais baixos do maciço montanhoso central bem como os morros isolados, sendo a formação vegetal que ocupa a maior extensão da Ilha, cerca de $74 \%$ da área total (MELO e MANTOVANI, 1994). De acordo com Giulietti et al. (1983) não ocorre uma uniformidade na cobertura florestal do maciço montanhoso central da Ilha. Esta variação na composição das espécies e na estrutura da cobertura florestal das encostas é devida às variações de umidade, dos tipos de solo e, em especial, à variação na temperatura, ao longo do gradiente de altitude.

A formação de floresta de encosta é caracterizada por apresentar variações estruturais muito grandes, pois este tipo de vegetação pode ser dependente de vários fatores como a cota de altitude em que se encontram, relacionadas à temperatura, os tipos de solos; a umidade vinda do oceano. A declividade do terreno não permite que o dossel filtre completamente a luz solar, favorecendo a presença de muitas epífitas e espécies características do estrato sub-bosque (MANTOVANI et. al., 1990).

A floresta não é muito densa, sendo formada por indivíduos de diferentes classes de altura e diâmetro. O componente arbustivo-herbáceo não é denso e o número de epífitos vascular é elevado. A distribuição vertical das alturas das copas 


\begin{tabular}{|l|r|}
\hline Recebido em: 10/12/2003 & HOLOS Environment, v.5 n.1, 2005 - P. 10 \\
\hline Liberado para Publicação em: 12/10/2005 & ISSN: 1519-8634 \\
\hline
\end{tabular}

das árvores é contínua, com maior densidade até $10 \mathrm{~m}$, que diminui gradativamente até as emergentes que alcançam até $35 \mathrm{~m}$.



Figura 3 - Florestal Pluvial Tropical de Encosta (foto - J.V.E.Bernardi).

\subsubsection{Formação Arbustiva dos Topos Montanhosos}

Nos picos dos morros na Ilha ocorrem mudanças na composição florística e fisionômica drástica em relação à floresta Pluvial Tropical de Encosta, com diminuição acentuada da altura dos indivíduos e no número de epífitas. Pode-se observar que algumas espécies ocorrem preferencialmente nos pontos mais altos da encosta como Leandra quinquedentata, Nidularia bilbergioides e Fuchsia regia. $\mathrm{O}$ aspecto geral é de uma vegetação de região mais seca, devido aos ventos fortes que diminuem a umidade e por receberem água somente das chuvas que caem diretamente nessas porções de topo.

A formação arbórea presente é sempre mais baixa, apresentando um estrato inferior bem desenvolvido, as epífitas diminuem consideravelmente e a vegetação herbácea é dominante. Ainda, observa-se em locais onde a ação do vento é parcialmente interrompida, um maior número das espécies que alcançam cerca de 2 metros de altura, composta de elementos florísticos típicos da restinga.

\subsubsection{Vegetação Secundária}

A vegetação secundária encontrada na Ilha do Cardoso deve-se principalmente a atividades agrícolas desenvolvidas desde o século XVIII. Com a transformação da Ilha, na última década de 60 século XX, em Parque Estadual, ocorreu um abandono das áreas de cultivo, desencadeando nestas áreas um processo de auto-regeneração e sucessão florestal.

Segundo Noffs e Baptista-Noffs (1982) na evolução sucessional da vegetação secundária existe uma nítida tendência de aumento no número árvores em relação a vegetação de restinga. As espécies Cecropia pachystachia e Senna multijuga são 
espécies características destas áreas de vegetação secundária. Algumas espécies ligadas às atividades antrópicas, também são encontradas como Anacardium occidentalis (cajueiro) e Coffea arábica (cafeeiro).

A vegetação secundária pode ser encontrada ainda, em regiões de encostas afetadas por deslizamentos. Nessas áreas, encontram-se manchas de taquaras, com espécies que atingem até $30 \mathrm{~m}$ de altura entre as quais se pode citar: Schizolobium parahyba e Euterpe edulis. Este tipo de vegetação atualmente apresenta um alto grau de desenvolvimento e complexidade, o que torna difícil a sua separação em relação às florestas pluviais tropicais típicas das encostas.

\subsubsection{Vegetação de Mangue}

$\mathrm{Na}$ Ilha do Cardoso a vegetação de mangue cobre os sedimentos finos e lodosos da planície litorânea encontrados na foz dos rios e ao longo do canal de Ararapira, constituindo os manguesais. Segundo Schaeffer-Novelli (1987) os mangues da Ilha do Cardoso apresentam padrão idêntico aos demais mangues da costa brasileira.

Em termos ecológicos, os mangues caracterizam-se pela presença de substrato constituído por sedimentos não consolidados, permanentemente inundado, pobre em oxigênio e rico em matéria orgânica. As espécies vegetais adaptadas a essas condições extremas são poucas, e se repetem por todo o litoral brasileiro. Na Ilha são encontradas as espécies Rhizophora mangle (Rhizophoraceae), com suas características raízes escora, Laguncularia racenosa (Combretaceae) e Avicennia schaueriana (Verbenaceae). Nas bordas dos manguezais, por sua vez ocorrem comumente Hibiscos pernambucensis (Malvaceae) e Spartina ciliata (Graminea).

\section{PROCEDIMENTOS E TÉCNICAS EMPREGADAS}

\subsection{Marcação dos pontos de amostragem com auxílio do GPS}

Para a marcação dos transectos e pontos de coleta de dados, utilizou-se, neste trabalho, três cartas altimétricas para formar o mapa base, imagens de satélite LANDSAT-TM e fotografias aéreas na escala 1:35.000. As cartas altimétricas adotadas foram: Cartas do Ministério do Exercíto-Departamento de Engenharia e Comunicação - Folha Cananéia (SG-23-V-GI-1 - MI-2845/1); Folha Barra do Ararapira (SG-23-V-GI-1 - MI-2844/4) e carta do IBGE - Folha Ariri (X-D-III-2 MI2844/2), na escala 1:50.000, digitalizada em AutoCAD R14 (AUTODESK, Inc.1997). Devido às distorções desta carta tornou-se necessário nova digitalização e uma correção no georreferenciamento, feito com auxilio do GPS.

O Sistema de Posicionamento Global (GPS) é um sistema multipropósitos, que permite ao usuário determinar sua posição expressa em latitude, longitude, altura geométrica ou elipsoidal, velocidade e o tempo em relação a um sistema de referência definido para qualquer ponto sobre ou próximo da superfície terrestre. A grande 
vantagem deste sistema é a sua capacidade de integração com outros sistemas, ressaltando sua integração com o Sistema de Informação Geográfica (SIG), capaz de produzir mapas digitais em tempo real com alta precisão.

O GPS utilizado foi o modelo GARMIM 48, que opera em módulo diferencial, permitindo assim uma precisão com um erro que pode variar de 1 a $5 \mathrm{~m}$. Desta forma, foram medidos dois pontos com marcos testemunhos conhecidos da Marinha Brasileira, sendo o primeiro no Morro do Pereirinha, localizado junto a Base do Parque (marco $\mathrm{n}^{\circ} 81091$ ) e o segundo no marco do Tratado de Tordesilhas, localizado na Ponta de Itacuruçá, à leste da Ilha. A partir destes dois pontos conhecidos foram realizadas 12 horas de medições para cada ponto com GPS, sendo armazenadas as leituras a cada 30 minutos para as correções. Internamente este GPS possui um sistema de armazenamento que permite ao equipamento armazenar as medidas a cada 15 segundos, fornecendo assim durante os 30 minutos o valor médio das leituras.

Foi usado também, de modo auxiliar, um sensor DGPS diferencial, modelo GBR21, consistindo resumidamente em captar sinais do satélite e de uma estação de rádio conhecida (neste caso os sinais de rádio da Ilha da Moela, próxima de Santos). Assim o receptor de GPS fez a correção automaticamente com um erro aproximado de 15 metros e o sensor corrigiu a leitura com um erro que varia de 1 a 5 metros. As comparações feitas das leituras do GPS corrigidas com as dos marcos permitiram um ajuste em torno de 2 metros para a ponta do Itacuruçá e 3 metros para o Morro do Pereirinha. Para o restante dos pontos levantados, a precisão média foi de 2 metros com um desvio padrão médio de 1,5 metros.

\subsection{Obtenção de modelo 3D para a área de estudo.}

Para a confecção da representação do mapa topográfico tridimensional, a partir de um bidimensional, foi gerado o Modelo Digital de Elevação (MDE), utilizando-se dos seguintes programas: AutoCAD R14, com algumas rotinas no formato "LSP"; “DXF2DAT"; SURFER 8; COREL 9.0.(COREL DRAW, 1999).

Com o auxílio do programa AutoCAD R14, para a entrada dos dados, digitalizou-se em mesa apropriada as curvas de nível extraídas das cartas topográficas mencionadas no item anterior. Criou-se, então, um mapa bidimensional com as cotas de elevação em escala 1:50.000. Com o objetivo de evitar os exageros verticais do MDE, trabalhando-se ainda com o mesmo programa, utilizou-se o comando "change" para alterar a altitude das cotas altimétricas, dividindo por 1000 o valor de todas as cotas. Os valores das cotas podem também ser obtidos pelo uso da rotina "topo.lsp".

Transformou-se o arquivo de extensão "dxf" em extensão "dat" com o auxilio do programa "DXF2DAT", dentro do ambiente DOS. Com auxílio do programa SURFER gerou-se uma superfície 3D, tendo sido criada uma malha 3D do mapa topográfico. Para esta finalidade o primeiro passo foi gerar um arquivo com extensão "grd". Para tanto se escolheu o algoritmo "Inverso da Distância ao Quadrado (IQD)" como método de interpolação. A partir daí, gerou-se um mapa de contorno (isolinhas) da altitude para sobreposição com a superfície 3D. Com as duas janelas abertas, a da 
malha "grd" e a do mapa de contorno, editou-se o "overlay" para sobreposição e escolha do ângulo de visada.

Para edição final do modelo 3D resultante, utilizou-se o programa COREL que permitiu a realização de uma série de ajustes gráficos, além da possibilidade de retoques com finalidades estéticas.

\subsection{Aquisição e tratamento digital das imagens de satélite}

\subsubsection{Seleção das imagens}

Foi utilizada uma imagem orbital do satélite Landsat 5, órbita 220 e ponto 77 , quadrante D, em duas passagens, datadas de 18/07/94 e 08/06/97, adquirida junto ao Instituto Nacional de Pesquisas Espaciais (INPE), com bandas 1,2,3,4,5,6 e 7, corrigidas radiométrica e geometricamente em nível 5.

\subsubsection{Tratamento das imagens}

Como técnicas de pré-processamento da imagem foram realizadas correções geométricas, uma vez que o formato "tiff" não as oferece, e técnicas de realce pelo emprego de contraste. As distorções geométricas sistemáticas, em um Nível 5 de correção, são realizadas pelo INPE pelo método de Reamostragem pelo Vizinho mais Próximo. Já as correções geométricas não sistemáticas, foram corrigidas pelo georreferenciamento da imagem "tiff".

Para iniciar o tratamento das imagens orbitais, foi necessário realizar a conversão do formato "dat", originalmente atribuído pelo INPE, para um formato que possibilitasse interface com os software" utilizados no estudo. A utilização do programa 2LTIFF, fornecido pelo INPE para a conversão da imagem ao formato "tiff", permitiu a compatibilização necessária.

Para o georreferenciamento da imagem foram selecionados alguns pontos de fácil identificação. A seguir obteve-se as coordenadas geográficas de tais pontos por meio de sua identificação na carta topográfica correspondente ou no campo. Os pontos coletados em campo (pontos de controle) tiveram suas coordenadas obtidas pelo uso de GPS e foram então registrados na imagem. Para tanto, se utilizou o módulo RESAMPLE do programa IDRISI 2.0 (THE IDRISI PROJECT, 1999), depois da conversão da imagem para o formato "img", no módulo de importação TIFIDRISI. Foi criado um arquivo de correspondência entre pontos de coordenadas conhecidas e os respectivos pixels que os representavam na imagem digital.

\subsubsection{Composição colorida e Análise das Componentes Principais}

A análise das componentes principais foi feita com o objetivo de determinar quais bandas apresentariam a maior percentagem de variação para a composição colorida. Para isso, realizou-se o seguinte procedimento: foi gerada uma matriz padronizada de variâncias-covariâncias no modulo "Analysis/Image Processing/Transformations, comando PCA". A partir desta matriz foi realizada a 
análise das componentes principais, para posterior escolha das bandas com maior porcentagem de correlação, referente à formação da imagem.

\subsubsection{Tratamento do realce por contraste}

$\mathrm{O}$ realce da imagem foi feito com o objetivo de melhorar o contraste das bandas escolhidas através da analise das componentes principais. Para tanto, utilizouse o software IDRISI, módulo "Analysis/Image Processing/Enhancement, comando Stretch", aplicando a técnica de contraste Linear com Saturação de 5\% para as três bandas escolhidas, significando um corte de $2,5 \%$ de cada lado do histograma dos tons de cinza ( 0 a 255), permitindo assim a exclusão dos tons muito escuros e dos muito claros das bandas.

\subsection{5. Índices de vegetação}

Para evidenciar características da vegetação foi utilizado o Índice de Vegetação (IV) proposto por Campbell (1987), que é o mais utilizado e denominado índice de vegetação de diferença normalizada (NDVI), conforme a seguinte equação:

$$
N D V I=\frac{I R-R E D}{I R+R E D}=\frac{T M 4-T M 3}{T M 4+T M 3}
$$

Onde: IR é o comprimento de onda da reflectância no infravermelho; RED o comprimento no vermelho; TM 3 corresponde à banda de freqüência 3 e a TM 4 corresponde à banda 4. Outro método utilizado com as imagens para a obtenção da densidade de vegetação é o de tons de cinza do pixel. Estes tons que apresentam valores 0 a 255 são utilizados para designar a reflectância que por sua vez indica a densidade de vegetação. O modulo utilizado na obtenção do índice de vegetação foi o "Analysis/Image Processing/Restoration, comando NDVI", usando para a composição as bandas 4 e 3 .

\subsection{Emprego da classificação digital da imagem}

Para a elaboração do mapa temático da vegetação da Ilha realizou-se a Classificação Supervisionada da imagem orbital. Adotou-se para esta finalidade a composição colorida feita anteriormente após a correção do contraste.

A Classificação Supervisionada consiste no processo de se usar amostras de pixels da imagem, de identidade conhecida, com o intuito de classificar os pixels de identidade desconhecida. Uma vez que o trabalho em campo possibilitou o conhecimento da composição da vegetação e sua correlação com a imagem de satélite em grande parte da Ilha, foi possível realizar a classificação supervisionada. Foram delimitadas na imagem amostras de áreas homogêneas e de identidade conhecida, chamadas de áreas de treinamento.

Dentre os diversos classificadores existentes, utilizou-se o método da Máxima Verossimilhança. Este classificador avalia a variância e a covariância dos padrões de 
resposta espectral, de cada pixel desconhecido, classificando-o para um padrão estabelecido.

De acordo com Lillesand e Kiefer (1994), deve-se assumir a distribuição normal dos dados das amostras de treinamento para cada categoria. Assumindo então esta condição os padrões espectrais podem ser descritos pelo vetor de médias e matriz de covariância. Desta forma podemos computar a probabilidade estatística da classe do pixel, estabelecendo a qual classe o pixel deve pertencer, escolhendo para tal a classe de maior probabilidade.

\section{RESULTADOS E DISCUSSÕES}

A topografia em uma representação tridimensional pode ser visualizada na Figura 4. O Modelo Digital de Elevação gerado adequou-se fielmente às características geomorfológicas verificadas em campo. O algoritmo IQD, usado na interpolação da superfície 3D, apresentou resultados satisfatórios, permitindo separar de forma bem evidente os três domínios geomorfológicos da Ilha. $\mathrm{O}$ angulo de rotação adotado foi de $23^{\circ}$ para oeste, destacando a porção sudeste.

O contorno da planície costeira, em amarelo, em torno da região montanhosa, em vermelho-alaranjado, mostrou-se fidedigno. As três interrupções nesse contorno, na área dos cordões arenosos no sul, podem ser observadas com a mesma disposição representada. Também para a área montanhosa o método mostrou-se acertado, uma vez que não se verificou exagero vertical na representação dos picos dos morros. Além disso, ficou evidenciado claramente o primeiro compartimento geomorfológico da Ilha, denominado de domínio montanhoso, desenvolvido em rochas sienitomonzoníticas, formando topos angulosos com vertentes retilíneo-convexas encaixadas no conjunto de fraturas de direção preferencial NE-SW, NW-SE e W-E de sudeste/noroeste. No ângulo de rotação adotado para a visualização, destacam-se as vertentes de NW-SE. Observa-se que a rede de drenagem está encaixada no fraturamento e é muito densa, formando calhas retilíneas com alto gradiente de inclinação.

A representação topográfica em três dimensões permitiu ainda analisar as áreas sombreadas do terreno, onde os pixels correspondentes apresentaram valores numéricos digitais (DNs) muito baixos. Os dados de radiação obtidos em campo comprovam que estas vertentes de SE são mais sombreadas e mais úmidas, quando comparadas com as vertentes de NW/NE. 


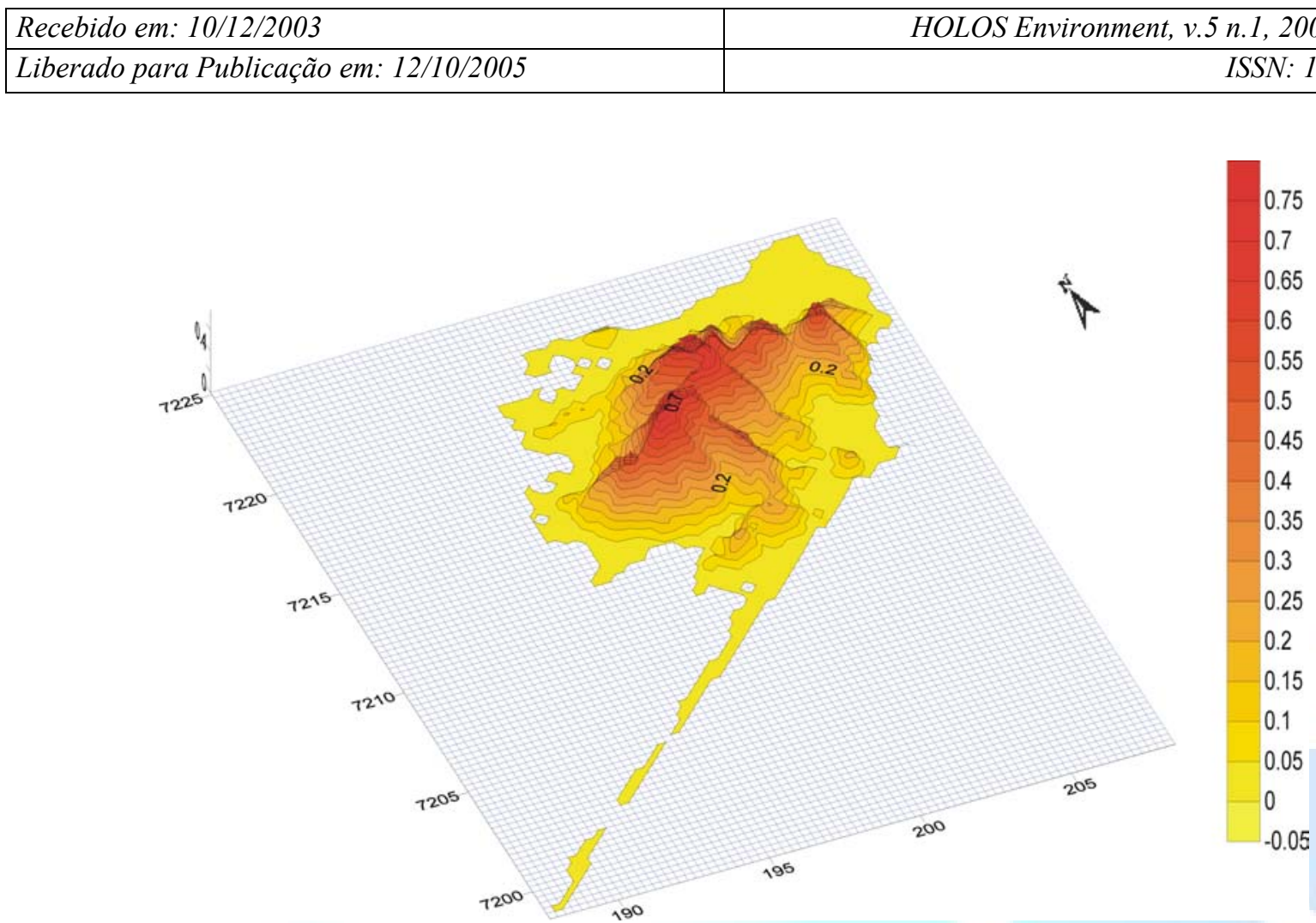

Figura 4 - Superfície 3D do Parque Estadual da Ilha do Cardoso.

Para a obtenção do mapa temático resultante da classificação da imagem de sensoriamento remoto, as datas de passagem do satélite (18/07/94 e 08/06/97) foram determinadas pela ausência de nuvens, pois segundo levantamento do INPE estas eram as únicas datas disponíveis sem cobertura de nuvens.

Para se determinar as bandas que ofereciam maior número de informações sobre a reflectância do terreno, foi aplicada a análise das componentes principais. Esta técnica ordenou as bandas 1, 2, 3, 4, 5 e 7 por ordem de importância a partir da percentagem de variação dos pixels de cada uma.

As componentes principais mostraram que as bandas 4 e 5 foram as mais importantes com cargas 0,9787 e 0,9623 sucessivamente para a primeira componente. Para a segunda componente a banda 3 apresentou a maior carga, da ordem de 0,9067. A primeira componente explica $85,83 \%$ da formação da imagem e a segunda componente explica apenas $8,89 \%$.

A partir da análise das componentes principais que definiu as bandas 4,5 e 3 como as mais importantes, iniciou-se o tratamento de realce da imagem.

O tratamento de realce da imagem fez-se necessário para melhorar o contraste de cada imagem, optando-se pela técnica linear. A redução de 5\% no histograma de freqüências pelo método linear de saturação, melhorou o contraste das bandas, com as quais iniciou-se a composição colorida.

A escolha das bandas para a composição colorida foi realizada com base na análise das componentes principais, que indicou as bandas 3, 4 e 5 como as mais importantes para a formação a imagem colorida (Figura 5). O resultado obtido permitiu diferenciar pelo menos seis tipos de vegetação. Estes tipos são: vegetação pioneira de dunas, em cor rósea; em cor verde escuro à floresta pluvial tropical de 
planície costeira; floresta pluvial tropical de encosta em cor verde limão, correspondendo a maior área de ocorrência; em verde claro a vegetação de restinga; vegetação de restinga de scrub e vegetação arbustiva dos topos montanhosos, cor verde-amarelada; e a cor marrom-esverdeada, corresponde às áreas com vegetação de mangue. A vegetação secundária não pode ser diferenciada pela composição colorida, motivo este relacionado ao grau de desenvolvimento florestal destas áreas, o qual é muito semelhante ao da floresta pluvial de planície litorânea.

Também na imagem correspondente ao Índice de Vegetação (NDVI), são bem realçadas as formações vegetais encontradas na Ilha confirmando a imagem em composição colorida, que indicou seis tipos de vegetação (Figura 6). Apesar das cores das duas imagens apresentarem diferenças para os mesmos tipos de vegetação, houve correlação espacial entre as mesmas formações florestais.

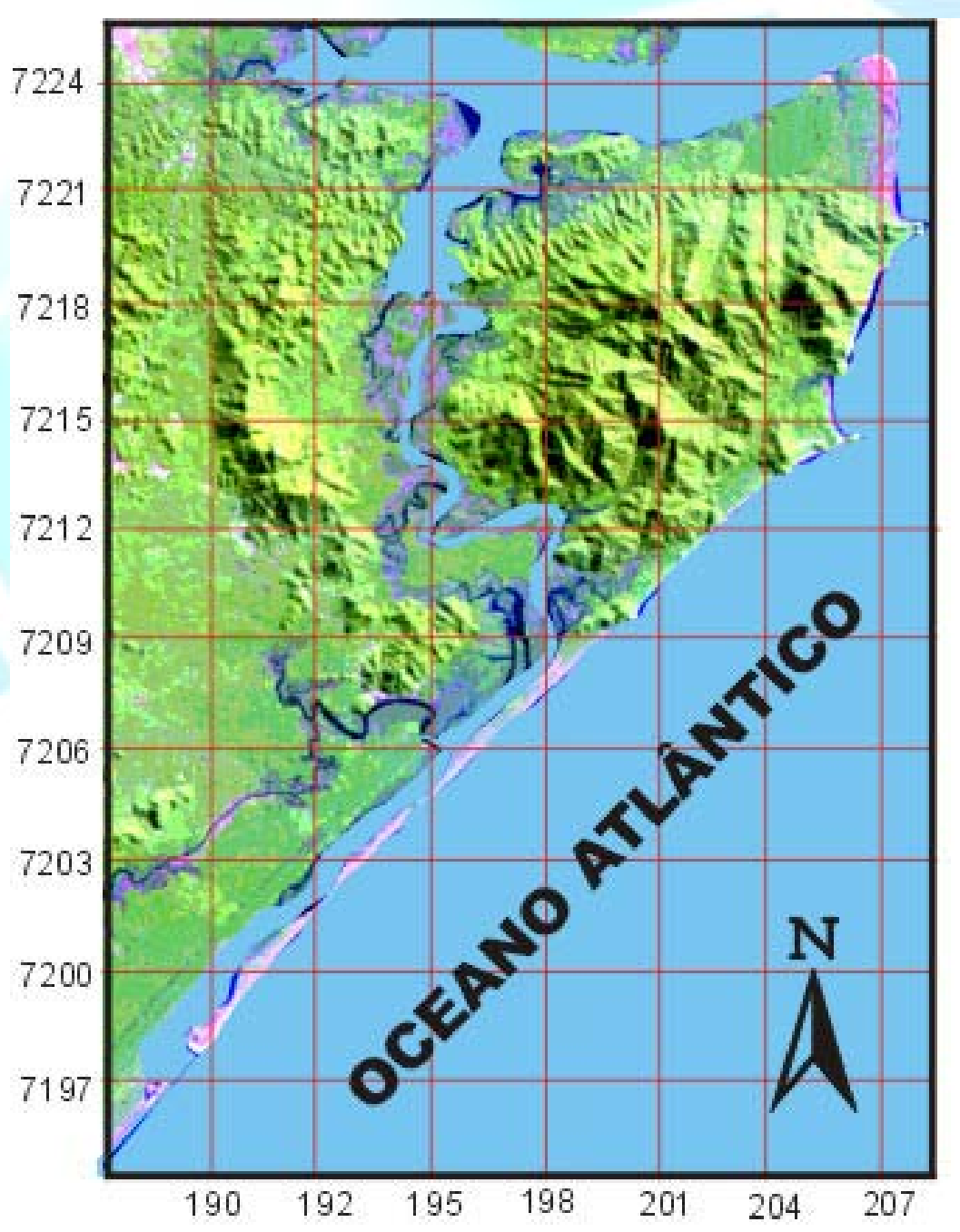

Figura 5 - Composição colorida RGB (543) georreferenciada.

A partir da definição espacial dos seis tipos de vegetação e com base no conhecimento de campo sobre a vegetação e sua posição geográfica foi possível realizar a classificação supervisionada pelo método da Máxima Verosimilhança. 


\begin{tabular}{|l|r|}
\hline Recebido em: 10/12/2003 & HOLOS Environment, v.5 n.1, 2005 - P. 18 \\
\hline Liberado para Publicação em: 12/10/2005 & ISSN: $1519-8634$ \\
\hline
\end{tabular}

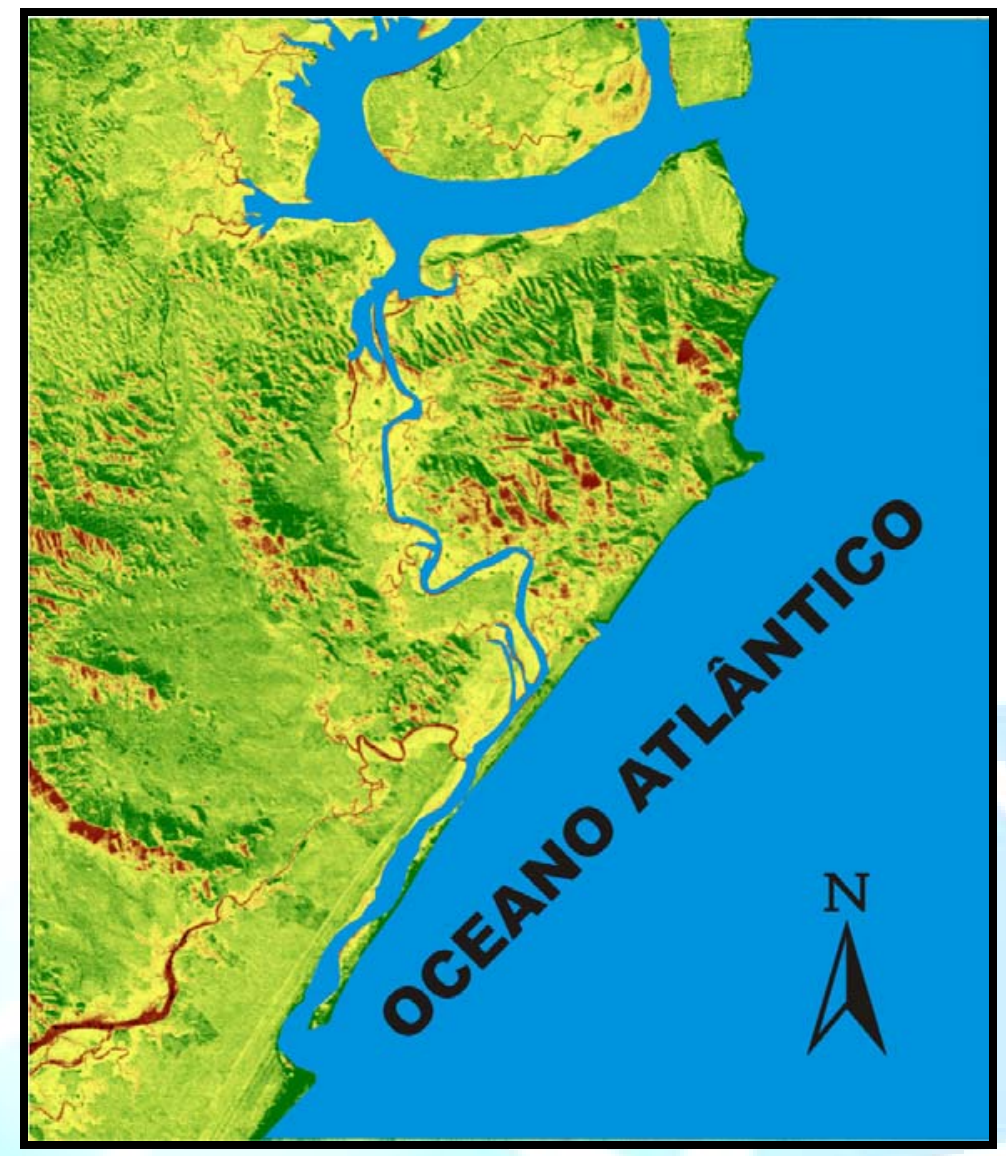

Figura 6 - Composição NDVI (bandas 4 e 3).

O mapa temático criado a partir da classificação supervisionada (Figura 7), mostra a fisiografia da vegetação de forma coerente com os dados observados em campo. A imagem formada pela classificação confirma espacialmente os tipos florestais encontrados nas imagens digitais, oriundas das composições coloridas e NDVI.

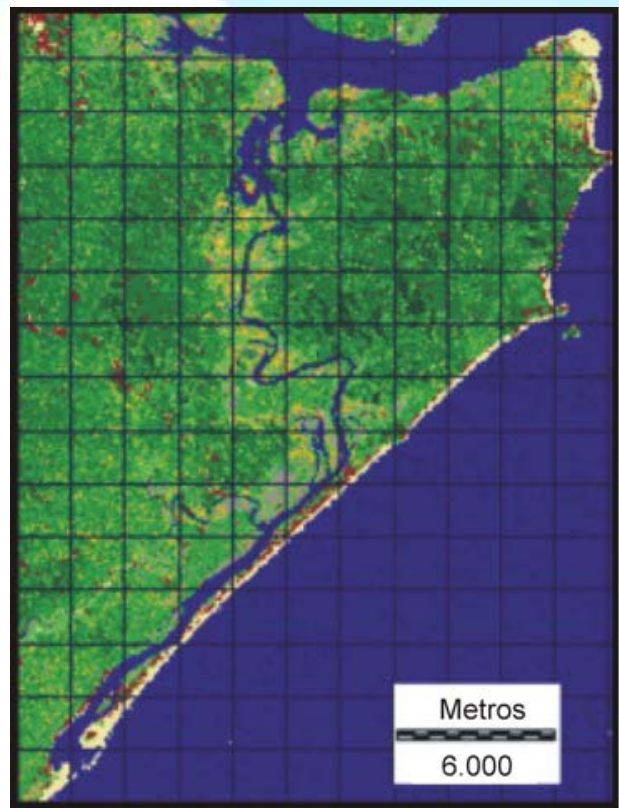

CLASSIFICAÇÃO VEGETAÇÃO POR IMAGEM ORBITAL

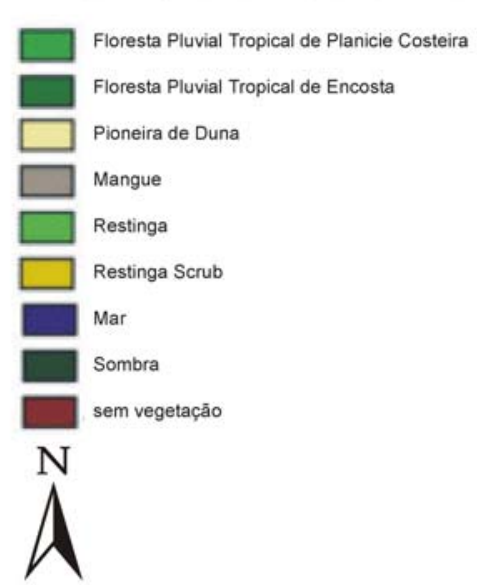

Figura 7 - Mapa temático dos tipos de vegetação do Parque Estadual da Ilha do Cardoso. 


\section{CONSIDERAÇÕES FINAIS}

As técnicas de sensoriamento remoto utilizadas neste trabalho permitiram a obtenção do mapa temático das composições colorida e NDVI. Os tipos de vegetação existentes encontram-se em um gradiente de vegetação com vários mosaicos desde a planície costeira até a região serrana. Nas áreas de mosaicos a vegetação está em franco estado de sucessão ecológica, provavelmente provocada por deslizamentos de solo ou ainda podendo tratar-se de áreas com afloramento rochoso, onde a vegetação aparece na forma de arbustos.

O gradiente de vegetação encontrado está relacionado com os diferentes tipos de substrato (rocha/solo), pois os limites são coincidentes com os das vegetações, indicando assim, uma dependência espacial. Nos Neossolos Quatzarênicos Hidromórficos típicos a vegetação corresponde à pioneira de dunas e restinga de scrub e nos Espodossolos Ferrocárbicos Hidromórficos hísticos encontra-se a vegetação de restinga (arbórea). No sopé da região montanhosa, encontra-se o solo Neossolos Flúvicos Distróficos típico com a floresta pluvial tropical de planície litorânea. Para a área montanhosa os solos correspondentes são Argilossolos Amarelos Distróficos câmbicos, Argissolos Vermelho-Amarelos Distróficos abrúpticos, Cambissolos Hísticos Distróficos típicos e Neossolos Litólicos Hísticos típicos. Com exceção do ultimo tipo, que possui uma vegetação arbustiva, os outros tipos de solos apresentam a floresta pluvial tropical de encosta. Apesar da vegetação de mangue ter sido evidenciada nas imagens digitais, não foi possível um acompanhamento detalhado de campo.

\section{AGRADECIMENTOS}

À Fundação de Amparo à Pesquisa do Estado de São Paulo/FAPESP pelo apoio financeiro (Processo 97/06545-5) e bolsa de doutorado (Processo 97/06546-0), ao Instituto Florestal do Estado de São Paulo pela permissão de efetuar a pesquisa na Ilha do Cardoso e aos funcionários do Parque Estadual da Ilha do Cardoso pela ajuda. Agradecimentos também são prestados aos três relatores, os quais com suas críticas construtivas em muito contribuíram para a melhoria do texto.

\section{REFERÊNCIAS}

AUTOCAD Release 14.0.Autodesk, Inc.Copyright @,1992-1997.

BARROS, F., MELO, M.M.R.F., CHIEH, S.O.C., KIRIZAWA, M., WANDERLEY, M.G.L.; JUNK-MENDAÇOLLI, S.L. Caracterização geral da vegetação e listagem de espécies ocorrentes: In: FLORA FANEROGÂNICA DA ILHA DO CARDOSO, São Paulo, Instituto de Botânica, v. 1, 1991, 184p. 
BERNARDI, J.V.E. 2001. Estudo quantitativo da estrutura da vegetação do Parque Estadual da Ilha do Cardoso/SP. (Tese de Doutorado, em Geociências e Meio Ambiente), Instituto de Biociências, 2001, 174f.Universidade Estadual Paulista, Rio Claro, 2001.

CAMARGO, J.C.G.; PINTO, S.A.F.;TROPPMAIR, H. Estudo fitogeográfico e ecológico da bacia hidrográfica Paulista do Rio da Ribeira. São Paulo: IG/USP, Departamento de Geografia. 1972. (Série Biogeografia, 5).

CAMPBELL, J. B. Introduction to remote sensing New York. The Guilford, 1987.

THE IDRISI PROJECT, Idrisi 32 version I32, 01.[s;1.]: Clark Labs, 1999.

CORELDRAW Versão 9.0. [s.1.]: Corel Coporation \& Corel Corporation Limited., 1999.

CRÓSTA, A.P. Processamento digital de imagens de sensoriamento remoto. Campinas: IG/UNICAMP, 1993. 170p.

DE GRANDE, D.A; LOPES, E.A. Plantas da restinga da Ilha do Cardoso (São Paulo, Brasil) Hoehn. v.9: p.1-22, 1981.

EMBRAPA. Centro Nacional de Pesquisa de Solos. Sistema brasileiro de classificação de solos. Brasília, 1999. 412 p.

FUNARI, F. L.; STRUFFALDI-de VUONO; SALUM, S. T. Balanço hídrico de duas áreas de Mata Atlântica: Reserva Biológica de Paranapiacaba e Parque Estadual da Ilha do Cardoso (Estado de São Paulo). In: CONGRESSO DA SOCIEDADE DE BOTÂNICA SÃO PAUlO, 6, 1987, São Paulo. Anais do VI Congresso da Sociedade de Botânica de São Paulo: SBB, 1987. p.95-101.

GIULIETTI, A.M.; RIBEIRO FILHO, E.; BUENO, M.C.G.; AVELAR, W.E.P. Em busca do conhecimento ecológico: uma introdução à metodologia. São Paulo. [s.n.], 1983.

GOEL, N. S. Models of canopy reflectance and their use in estimation of biophysical parameters from reflectance data. Remote Sensing Reviews, New York, v.4, n.1, 1$122,1988$.

GOYOT, G. La Réflectance des Couverts Végétaux. Photo-Interprétation. Paris, v.33, p.157-180, 1995. 
GOYOT, G.; GUYON, D.; RIOM, J. Factors affecting the spectral response of forest canopies: a review. Geocarto International, Hong Kong, v. 4, n.3, p.3-18,1989.

KARMANN, I.; DIAS NETO, C.M.; WEBER, W. Caracterização litológica e estrutural das rochas metassedimentares do conjunto insular Cardoso, sul do Estado de São Paulo. Revista Brasileira Geociências, São Paulo. V. 29, n.2, p.157-162, 1999.

LILLESAND, T. M.; KIEFER, R. W. Remote sensing and image interpretation. $2^{\text {th }}$ ed. Chichester: Jonh Wiley. 1994. 750p.

LIU, H. Q.; HUETE, A. A feedback based modification of the NDVI to minimize canopy background and atmosphere noise. IEEE Transactions on Geoscience and Remote Sensing, v.33, n.2, p. 457-465.1995.

MANTOVANI, W; RODRIGUES, R.R.; ROSSI, L.; ROMANIUC NETO, S.; CATHARINO, E.L.M.;CORDEIRO, I. (1990). A vegetação na Serra do Mar em Salesópolis .In: Anais do Simpósio d Ecossistemas da Costa Sul e Sudeste Brasileira - Estrutura, função e manejo, Águas de Lindóia. São Paulo, Academia de Ciências do Estado de São Paulo. ACIESP 15.p.136-149.

MELO, M. M. R. F.; MANTOVANI, W. Composição Florística e Estrutura de Trecho de Mata Atlântica de Encosta, na Ilha do Cardoso (Cananéia, SP, Brasil). Bol. Inst. Bot, v.9, p.107-157, 1994.

NOFFS, M.S.; BAPTISTA-NOFFS, L.J. Mapa da vegetação do Parque Estadual da Ilha do Cardoso - as principais formações. In: CONGRESSO NACIONAL DE ESSÊNCIAS NATURAIS, 1982, Campos do Jordão. Anais... Campos do Jordão.1982, p. 613-619.

PETRI, S.; FÚLFARO, V.J. Nota sobre a geologia e terraços marinhos da Ilha do Cardoso. Notícias Geomorfológicas, Campinas, v.10, n.20, p. 21-31,1970.

SCHAEFFER-NOVELLI, Y. Manguezais brasileiros: região sudeste-sul. In: SIMPÓSIO SOBRE ECOSSISTEMAS DA COSTA SUL E SUDESTE BRASILEIRA.1987. Cananéia. Anais... São Paulo: 1987., v.1, p.78.

SURFER Golden Software Inc., versão 8.2002.

TUCKER, C. J. Red and photographic infrared linear combinations for monitoring vegetation. Remote Sensing of Environment, New York, v. 8, n.2, p.127-150, 1979. 
WEBER, W. Geologia e Geocronologia da Ilha do Cardoso, sudoeste da Estado de São Paulo. São Paulo. 1998. 87f. Dissertação (Mestrado em Geoquímica e Geotectônica), Instituto de Geociências, Universidade de São Paulo, 1998.

XAVIER, A. C. Estimativa de propriedades biofísicas de plantações de eucaliptos a partir de dados Landsat-TM. 1998. 98f. Dissertação de (Mestrado em Sensoriamento Remoto). Instituto Nacional de Pesquisas Espaciais, São José dos Campos.1998. 